\title{
Duff Aygıtı Tabanlı Seyrek Matris-Vektör Çarpımı
}

\section{Sparse Matrix-Vector Multiplication Based on Duff's Device}

\author{
Barış Aktemur ${ }^{1 *}$ \\ 1 Özyeğin Üniversitesi, Mühendislik Fakültesi, Bilgisayar Mühendisliği Bölümü, İstanbul, TÜRKIYE \\ Sorumlu Yazar / Corresponding Author*: aktemur@gmail.com

$\ddot{0} \mathbf{z}$

Seyrek matris-vektör çarpımı (SpMV) pek çok mühendislik probleminde ve bilimsel hesaplamada sıklıkla kullanılan bir işlemdir. SpMV'nin hızlandırılması geniş bir yelpazedeki uygulamaları olumlu etkiler. Bu makalede Duff aygıtı olarak bilinen döngü açılımının SpMV'nin başarımına etkisini irdeliyoruz. Önerdiğimiz Duff aygıtı tabanlı SpMV gerçeklemesi, en geçerli seyrek matris saklama formatı olan CSR formatının düșük maliyetli bir ön ișlemesi sonrası kullanılabilmektedir. Gerçek problemlerde kullanılan matrislerden oluşan veri kümesi ile deneysel bir değerlendirme yaptık ve önemli derecede hızlanma kaydedilebileceğini gözlemledik.

Anahtar Kelimeler: Seyrek matris-vektör çarpımı, yüksek başarımlı hesaplama, Duff aygıtı

\begin{abstract}
Sparse matrix-vector multiplication (SpMV) is used frequently in several engineering problems and scientific computation. Optimizing SpMV positively impacts a wide range of applications. In this paper, we investigate the effect of a loop-unrolling method known as Duff's device on the performance of SpMV. The Duff's device-based SpMV implementation that we propose can be used after a low-cost preprocessing of the CSR representation - the most common sparse matrix storage format - of a matrix. We have evaluated the approach on a dataset consisting of matrices from real-world problems, and observed that substantial speedup can be achieved.
\end{abstract}

Keywords: Sparse matrix-vector multiplication, high performance computing, Duff's device

\section{Giriş}

Seyrek matrisler, sonlu eleman modelleri, bilimsel benzetimler, makine öğrenmesi uygulamaları gibi pek çok bağlamda karşımıza çıkan, elemanlarının önemli bir kısmı sıfır olan matrislerdir. Seyrek matrislerle en sık yapılan işlemlerden birisi matrisin bir vektörle çarpımıdır. Özellikle yinelemeli çözümleyiciler için bu işlem kilit konumdadır. Bu nedenle seyrek matris-vektör çarpımının (SpMV) eniyilemesi üzerine yoğun araştırma yapılagelmiştir (örn. [1-10]).
Sıfır olan elemanların çarpma işleminin sonucuna bir katkısı olmadığı için ve de bellek alanından tasarruf etmek adına, seyrek matrisler sadece sıfır olmayan elemanlarının tutulduğu formatlarda saklanırlar. $\mathrm{Bu}$ formatların en yaygını Compressed Sparse Row (CSR) adı verilendir (Compressed Row Storage - CRS olarak da bilinir) [11]. Bu, genel-geçer bir formattır; bütün seyrek matrisler bu formatta tutulabilir. Doğrusal cebir kütüphanelerinin büyük çoğunluğu seyrek matris girdilerini CSR 
formatında kabul ettiklerinden, bu format defakto standart konumundadır.

Örnek bir seyrek matris ve onun CSR gösterimi Şekil 1'de verilmiştir. CSR formatında matrisin sıfır olmayan elemanları va ls adıyla anacağımız bir dizide tutulurlar; cols olarak anacağımız ikinci bir dizide ise bu elemanların sütun indisleri yer alır. Sıfır olmayan eleman sayısı NZ ise, bu iki dizinin uzunluğu da NZ'dir. Son olarak, rows ismiyle anacağımız üçüncü bir dizi ise her bir satırda yer alan elemanların vals ve cols dizilerinde hangi indisler arasında yer aldığ bilgisini tutar. Öyle ki, ardışık rows değerleri arasındaki fark, karşıllık gelen matris satırının uzunluğunu verir. Yani, i'ninci satırın uzunluğu rows[i+1]-rows[i] ifadesi ile bulunabilir. Matrisin satır sayısı $\mathrm{N}$ ise, rows dizisinin uzunluğu $\mathrm{N}+1$ 'dir.
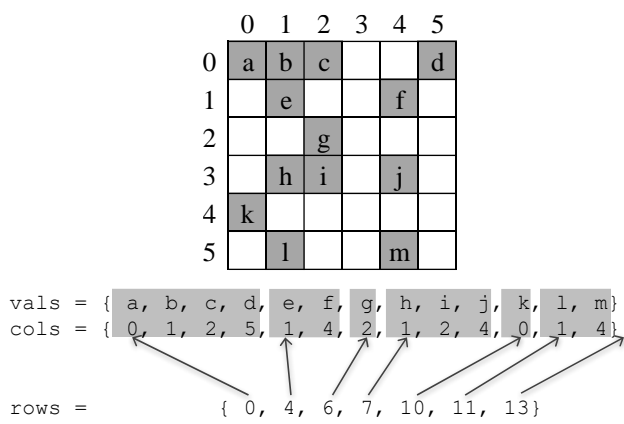

Şekil 1. Seyrek bir matris ve CSR gösterimi

CSR formatı kullanarak yapılan SpMV işleminin kodu ise Şekil 2'de gösterilmektedir $(\mathrm{C} / \mathrm{C}++$ dilinde). Burada $x$ girdi vektörü, y çıtı vektörüdür.

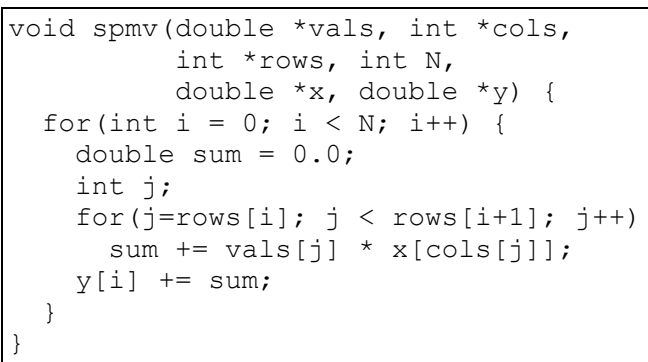

Şekil 2. CSR formatı ile yapılan SpMV'nin kodu

SpMV'de genel olarak yüksek başarım elde etmek zordur. Bunun nedeni, matris elemanlarının düzensiz bir șekilde konumlanmıș olması ve $x$ vektörünün elemanlarına erişimin dolaylı olmasıdır. Bu düzensiz ve dolaylı erişim, işlemci mimarilerinde başarımı etkileyen ana unsurlardan olan önbelleğin kullanımı, verinin önceden yüklenmesi gibi konularda verimsizliğe neden olmaktadır; ayrıca az elemanlı satırlarda iç döngünün yineleme sayısı çok düşük kalacağından dallanma kestirimi mekanizması etkisini gösterememektedir [4]. Belli eleman örüntülerine sahip birtakım seyrek matriste bu sorunların üstesinden gelmek ve başarımı artırmak için CSR'den başka matris saklama formatları kullanılabilir. Ancak CSR'den bu formatlara dönüşüm koşut-zamanda vakit kaybına neden olmakta ve çoğu zaman astarı yüzünden pahalıya gelmektedir. Pratikte, özel durumlara uygun çoğu format sadece matris örüntüsü koșut-zamandan önce (yani durağan zamanda) belli ise faydalı olabilmektedir. $\mathrm{Bu}$ nedenle koșut-zaman maliyeti düșük olan yöntemlere ihtiyaç duyulmaktadır [12-17].

$\mathrm{Bu}$ makalede, Duff aygitı olarak adlandırılan döngü açılımı marifetinin SpMV işleminin bașarımına etkisini irdeliyoruz. Duff aygitı yöntemiyle SpMV kodundaki iç döngüyü açıyor, ayrıca matrisin rows dizisi üzerinde bir veri küçültme işlemi yapıyoruz. Bu işlem sadece rows dizisi üzerinde değişiklik gerçekleştirdiğinden CSR'den dönüşüm maliyetleri düșük olmaktadır.

Bölüm 2'de Duff aygıtını ve SpMV kodunda nasıl kullanılabileceğini anlatıyoruz. Bölüm 3'te deneysel değerlendirmemizi sunuyoruz. Bölüm 4'te ilgili diğer çalışmaları değerlendiriyor, Bölüm 5'te makalemizi sonlandırıyoruz.

\section{Yöntem}

Döngü açılımı derleyiciler tarafından sıklıkla uygulanan eniyilemelerden biridir. Amaç, bir yanda döngünün sayaç masrafını azaltmak, bir yandan da tekrarlanan döngü vücudunda daha fazla eniyileme imkânı ortaya çlkarmaktır. Ancak bir dezavantajı vardır, o da döngünün yineleme sayısı açılım miktarının tam katı olmadığı durumlarda arta kalan yinelemeleri bitirmek için ikinci bir döngü eklemek gerekliliğidir. Şöyle ki, Șekil 2'de bulunan iç döngüyü 4 kere açmak istediğimizde aşağıdaki gibi bir kod elde ederiz:

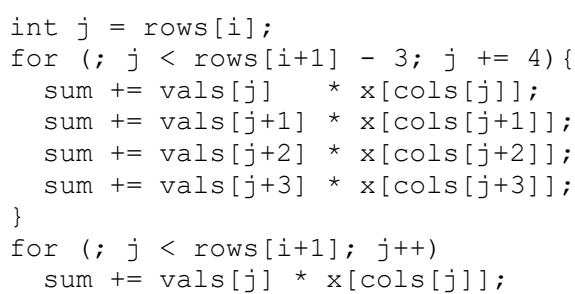


Burada, ikinci döngü ek kontrol yükü getirmektedir. Kısa matris satırları için bu yükler hissedilebilir seviyededir. İkinci döngüden kurtulmak adına literatürde Duff aygıtı [18] (Duff's device) olarak bilinen kodlama marifeti uygulanabilir. Bu yönteme göre

do

$s$

while $(--$ count $>0)$;

biçimindeki bir döngü, şu şekilde 4 kere açlabilir:

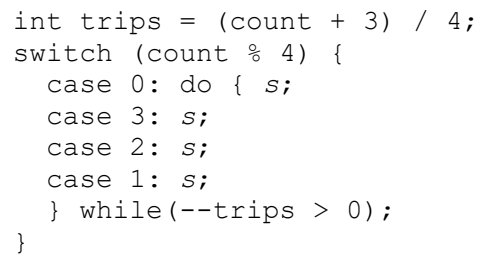

Burada uygulanan marifet, do-while döngüsü ile switch-case komutlarını iç-içe yazarak döngüye ilk giriş noktasının döngü vücudunun ortasında bir yer olmasını sağlamaktır.

Duff aygitından ilham alarak SpMV kodunu yeniden yazalım. Bunu iki sürüm halinde yapacağız. Her bir sürümü aşağıda bir alt bașlıkta inceliyoruz.

Duff aygıtının SpMV için kullanılması fikri yeni değildir. Bildiğimiz kadarıyla daha önce sadece Youssefi'nin yüksek lisans tez çalıșmasında incelenmiştir [19]. Duff aygıtının özgün hali döngünün en az bir kere çalışacağı varsayımına göre yazılmıştır. Youssefi'nin tezinde de boş satır içermeyen, bantlı yapıdaki 13 matris için denemeler yapılmıștır; kullanılan kod bos satır içeren matrisler için hata vermektedir. Ancak genel olarak seyrek bir matrisin hiç elemanı olmayan satırlarının olması mümkündür. Makalemizde verdiğimiz kodlar bu durum gözetilerek yazılmıștır. Bölüm 2.2'de sunduğumuz DuffCompressed $\mathrm{k}_{\mathrm{k}}$ yöntemi tamamen özgündür; bildiğimiz kadarıyla daha önce hiçbir çalışmada irdelenmemiştir.

\subsection{Birinci sürüm: DuffCSR $_{k}$}

Yukarıdaki Duff aygıtından ilham alarak, Şekil 2'deki SpMV kodunu Şekil 3'teki gibi yazabiliriz. Her ne kadar Şekil 3'te verdiğimiz kod, örnek teşkil etmesi açısından, döngünün 4 kere açılım uygulanmıș hali olsa da bunu rahatlıkla genelleyebiliriz. Döngüye $k$ kere açılım yapılması ile elde edilen koda $\operatorname{DuffCSR}_{k}$ diyelim. Bu durumda Şekil 3'te verdiğimiz kod $\mathrm{DuffCSR}_{4}$ olmaktadır.

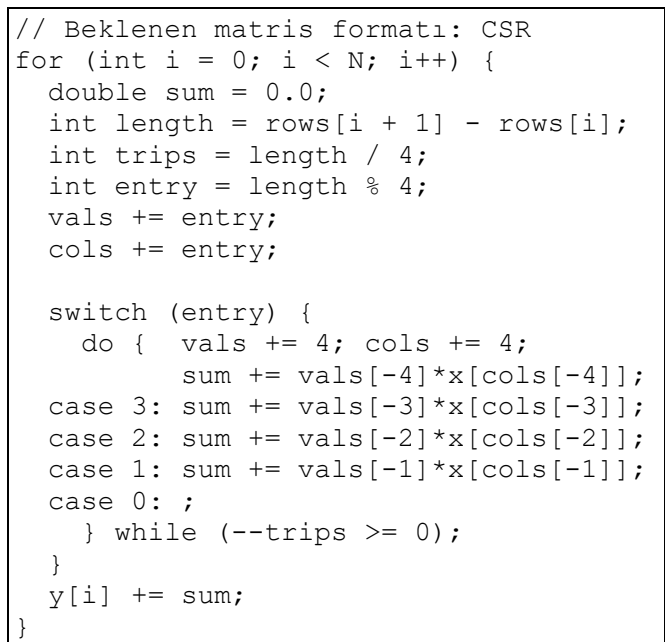

Şekil 3. Duff aygitı ile yazılan DuffCSR 4 yöntemi

$\operatorname{DuffCSR}_{k}$ kodu ile CSR formatı hiç değiştirilmeden SpMV yapilabilmektedir. Youssefi'nin tezinde ayrıca Duff aygıtı yaklaşımının LCSR seyrek matris formatı [20] kullanan hali de incelenmiștir. LCSR formatında matrisin elemanları yeniden sıralanmaktadır. $\mathrm{Bu}$ nedenle CSR formatından LCSR elde etmek için hem vals hem de cols dizilerinin yeniden olușturulması gerekir. $\mathrm{Bu}$ durum en baştan belirlediğimiz "düşük maliyet" kısıtına uymadığı için LCSR tabanlı yaklașımları kapsam dıșı tutuyoruz.

\section{2. İkinci sürüm: DuffCompressed ${ }_{k}$}

DuffCSR $k$ yönteminde her bir satırın uzunluğunu buluyor, sonra da bu değeri kullanarak döngü vücuduna giriş noktasını (entry) ve döngü yineleme sayısını (trips) hesapliyoruz. Bu hesaplamalardan kurtulmak adına entry ve trips değerlerini bir ön ișleme safhasında önceden hesaplayıp rows dizisinde tutabiliriz. Üstelik bunu daha düşük boyut kullanarak yapabiliriz. Şöyle ki, entry değeri her zaman $k^{\prime}$ den küçük olacaktır; trips'in alabileceği en yüksek değer ise matrisin azami satır uzunluğu bölü $k$ kadardır. Bu değerler yeterince küçükse, 4 baytllk int değerleri tutmak yerinde 1 veya 2 baytlık iki değer tutabiliriz. Böylece veri boyutunu zahmetsiz bir şekilde küçültme imkânından faydalanmış oluruz.

Bir matrisin azami satır uzunluğuna ASU diyelim. ASU $/ k$ değeri $2^{8^{\prime}}$ den küçük ise, olası tüm trips 
değerleri 1 baytlık alanda gösterilebilir. Benzer şekilde, $k$ değeri $2^{8^{\prime}}$ den küçükse, tüm entry değerleri 1 baytlık alanda tutulabilir. $\mathrm{Bu}$ durumda matrisin her bir satırı için iki adet unsigned char verisi tutariz. Orijinal rows dizisinde ise her bir satır için 4 baytlık bir int değer tutuluyordu. (unsigned char veri tipi günümüz işlemcilerinin çoğunda, örn: X86 mimarisi, 1 bayt iken, int veri tipi 4 bayttır.) Böylece rows dizisi için gereken alan yarıya indirilmiș olacaktır. $\mathrm{Bu}$ dönüșümü CSR formatındaki rows dizisini Şekil 4'teki gibi ön işlemeden geçirerek yapabiliriz. Dikkat ediniz ki bu dönüşümde orijinal rows dizisi üzerinde değişiklik yapıyoruz, ancak istenirse yeni bir alan da açılabilir.

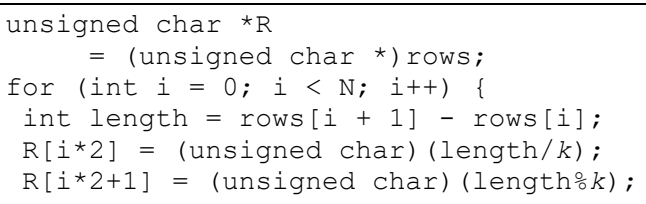

Şekil 4. CSR formatındaki rows'un ön işlenmesi

Yeni rows dizisini kullanarak SpMV işlemini Șekil 5'teki gibi yapabiliriz. $\mathrm{Bu}$ yönteme DuffCompressed $_{k}$ diyoruz. DuffCSR $R_{k}$ yönteminin koduna kıyasla değişim gösteren yerler koyu yazı tipi ile gösterilmiştir.

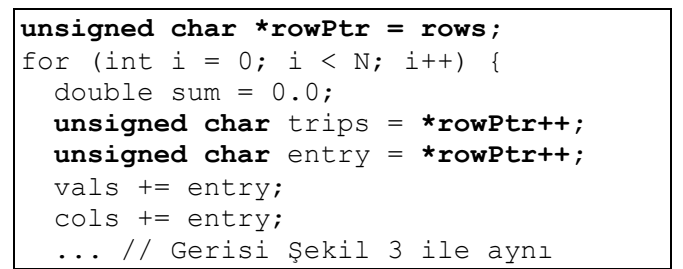

Sekil 5. Ön ișlemeden geçirilmiș rows dizisi kullanan DuffCompressed 4 kodu

Eğer ASU/ $k$ değeri $2{ }^{8}$ den küçük değil ama $2^{16}$ 'dan küçükse, entry ve trips değerlerini tutmak için unsigned char yerine 2 baytlık unsigned short veri tipi kullanırı. (Burada entry değerlerini unsigned char, trips'i ise unsigned short olarak tutarak $1+2$ bayt tarzında bir veri düzenini hafiza hizalama sorunlarına yol açacağı için kullanmadık.) $\mathrm{Bu}$ durumda her bir satır için $2+2=4$ baytlık alan kullanacağımız için yerden kazanç sağlamayız, fakat yine de entry ve trips değerlerini bölme ve kalan alma ișlemleri ile hesaplamak yerine hazır hesaplanmış olarak okuma imkânımız vardır.
Eğer ASU/k değeri 216'dan da küçük değilse DuffCompressed $_{k}$ yönteminde entry ve trips değerlerini önceden hesaplamıyoruz; yeni rows dizisinde sadece satır uzunlarını (length) saklıyor, entry ve trips'i SpMV çalışırken length değerinden hesapliyoruz.

\section{Bulgular}

$\mathrm{Bu}$ bölümde Duff aygitı tabanlı SpMV gerçeklemesinin başarımını değerlendiriyoruz. Bunun için oluşturduğumuz bir veri kümesindeki her bir matris için SpMV yöntemlerini çalıștırıp sürelerini ölçtük. Deneyleri iki farklı bilgisayarda yaptık. Așağıda deney detaylarını veriyor ve elde edilen sonuçları tartışıyoruz.

\subsection{Dayanak yöntemler}

Duff aygıtı tabanlı SpMV gerçeklememizin başarımını ölçmek için referans noktası olarak öncelikle CSR yöntemini kullanacağız. Buna ek olarak ikinci bir yöntem daha kullanacağız. Hatırlayalım ki, DuffCompressed $k$ yönteminde rows dizisi için kullanılan veri alanını küçültme imkanını değerlendiriyoruz. DuffCompressed $k$ yöntemiyle elde edilebilecek hızlanmanın ne kadarı veri küçültmesinden, ne kadarı ise Duff aygitı kullanımından kaynaklanıyor, bunu anlayabilmek adına, CSRLen ismini verdiğimiz, CSR'ye çok benzeyen ve veri küçültme kullanan bir yöntemi daha kıyaslama için kullanacağız. Bu yöntemde öncelikle rows dizisini aşağıdaki ön işlemeden geçirip her satırın uzunluğunu buluyor, rows dizisinde bu değerleri tutuyoruz.

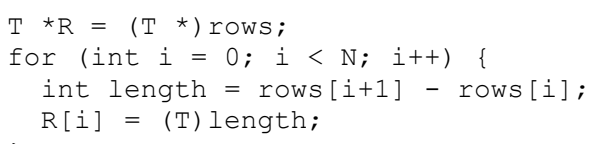

Burada $T$ veri tipi olarak, eğer azami satır uzunluğu $2^{8}$ den küçükse unsigned char, $2^{8}$ ile $2^{16}$ arasindaysa unsigned short, o da değilse unsigned int kullaniyoruz. $\mathrm{Bu}$ değişiklik sonucu CSRLen yöntemi Şekil 6'daki gibi yapılır.

CSRLen'de, DuffCompressed $k$ yöntemindeki gibi, hatta daha üstün, alan kazanımları elde edilebilir. $\mathrm{Bu}$ sebeple, DuffCompressed $k$ yönteminin başarımını CSRLen ile kıyaslayarak başarımın ne kadarının veri küçülmesinden ne kadarının Duff aygıtı yaklaşımından kaynaklandı̆̆ı hakkında fikir yürütebiliriz. 
DEÜ FMD 22(65), 315-324, 2020

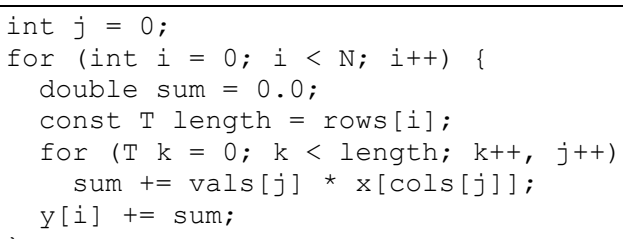

Şekil 6. CSRLen formatı ile yapılan SpMV

CSRLen yöntemi ICRS formatına [10,21] benzerlik göstermektedir. CSRLen formatında ardıșık değerler arasındaki farkın tutulması sadece rows dizisine uygulanırken, ICRS formatında hem rows hem de cols dizisine uygulanmaktadır. Düșük maliyet politikamız gereği rows dizisinden çok daha uzun olması beklenen cols dizisini ön işlemeden geçiren ICRS yöntemini kapsam dışı tuttuk.

\subsection{Deney kurulumu}

Deneyleri iki farklı bilgisayarda gerçekleștirdik. Bilgisayarların özellikleri Tablo 1'de verilmiștir. Kodları derlemek için bilgisayarda mevcut derleyiciyi -03 eniyileme seviyesinde kullandık.

Tablo 1. Deney bilgisayarları.

\begin{tabular}{|c|c|c|c|c|c|}
\hline \multirow{2}{*}{ İşlemci } & \multicolumn{3}{|c|}{ Önbellek (Bayt) } & \multirow{2}{*}{ Bellek } & \multirow{2}{*}{ Derleyici } \\
\hline & L1 (I/D) & $\mathrm{L} 2$ & L3 & & \\
\hline $\begin{array}{l}\text { AMD FX } \\
8350 \\
\text { PileDriver }\end{array}$ & $64 \mathrm{~K} / 16 \mathrm{~K}$ & $2 \mathrm{M}$ & $8 \mathrm{M}$ & $8 \mathrm{~GB}$ & $\begin{array}{l}\text { gcc } \\
5.4 .0\end{array}$ \\
\hline $\begin{array}{l}\text { Intel Xeon } \\
\text { E5-2620 } \\
\text { SandyBridge }\end{array}$ & $32 \mathrm{~K} / 32 \mathrm{~K}$ & $256 \mathrm{~K}$ & $15 \mathrm{M}$ & $16 \mathrm{~GB}$ & $\begin{array}{l}\text { icc } \\
17.0 .0\end{array}$ \\
\hline
\end{tabular}

Deneyleri Tablo 2'de listelenen matrisleri kullanarak gerçekleștirdik. Bu matrisler bașka çalışmalarda da veri kümesi içinde kullanılmıștır $[1,7,9,12]$; özellikleri geniş bir yelpazeye yayılmaktadır. Tabloda N matrisin satır ve sütun sayısını (tüm matrisler karedir), NZ sıfır olmayan eleman sayısını, NZ/N ortalama satır uzunluğunu (yani satır bașına ortalama eleman sayısını), ASU ise azami satır uzunluğunu vermektedir. Matrislerin tümü SuiteSparse (eski adıyla University of Florida) matris koleksiyonundan indirilebilir [22].

Her bir matris için CSR, CSRLen, DuffCSR ${ }_{k}$, DuffCompressed $_{k}$ yöntemleriyle SpMV ișlemi yaptık ve aldıkları süreyi ölçtük. Duff tabanlı yöntemlerde $k$ değeri olarak 4, 8, 16 kullandık. Ölçümleri șu sekilde gerçekleștirdik: Her bir matris için ölçüm yapılacak SpMV yöntemini bir döngü içinde çok defa yineledik (yineleme sayısı matris büyüklüğüne göre belirlenmektedir). Geçen zamanı ölçtük ve yineleme sayısına bölerek tek bir SpMV için geçen ortalama süreyi bulduk. Bunu 3 defa tekrarladık ve en düşük süreyi kaydettik. Böylece olası veri gürültüsünü asgari hale getirmeyi amaçladık. Her bir SpMV yönteminin başarımını CSR yöntemine göreceli hale getirdik. Bunun için, CSR yönteminin aldığı süreyi o yöntemin aldığı süreye böldük. $\mathrm{Bu}$ nedenle, başarım değeri 1'den büyük olduğunda CSR'ye kıyasla hızlanma kaydedildiğini, 1'den küçükse yavaşlama görüldügünü anlıyoruz.

\subsection{Sonuçlar}

AMD işlemcili deney bilgisayarında ölçülen bașarım değerleri Șekil 7'de, Intel ișlemcili bilgisayarda alınan sonuçlar ise Şekil 8'de yer almaktadır.

Genel olarak, DuffCompressed $k$ yöntemi $\operatorname{DuffCSR}_{k}$ 'den, $k=4$ durumu ise $k=8$ ve $k=16$ durumlarından daha iyi sonuçlar verdiğinden dolayı, sunumun sadeliği ve okunaklığını artırmak adına Sekil 7 ve 8'de Duff tabanlı yöntem olarak sadece DuffCompressed4'ün başarımını gösteriyoruz. Bu yöntemde dört matris için (ASIC_680k, circuit5M, FullChip ve ins2) ASU/k değeri $2^{16}$ dan büyüktür. Diğer matrislerden sekiz tanesi için (dc2, eu-2005, in2004, Stanford, Stanford_Berkeley, webbase-1M, wikipedia-20051105, wikipedia-20060925) ASU/ $k$ değeri $2^{8}$ ile $2^{16}$ arasında, kalan 18 matris içinse $2^{8^{\prime}}$ den küçüktür.

AMD ișlemcili bilgisayarda DuffCompressed 4 yöntemi 4 matris için CSR yönteminden daha kötü bașarım göstermiș, diğer matrisler için hızlanma sağlamıștır. En düşük bașarım 0,88x, en yüksek başarım $1,47 x$, ortalama başarım ise $1,09 \mathrm{x}$ olarak görülmektedir. Aynı bilgisayar üzerinde CSRLen yöntemi ile elde edilen bașarımın en yükseği $1,14 x$, en düșüğü $0,97 x$, ortalama ise $1,04 \mathrm{x}$ olmuştur.

Intel işlemcili bilgisayarda genel olarak daha düşük hızlanmalar görülmüştür. DuffCompressed 4 yöntemi 21 matris için hızlanma kaydetmiştir. En düşük başarım 0,88x, en yüksek başarım $1,17 x$, ortalama bașarım ise $1,03 x$ olmuştur. CSRLen yöntemi ile alınan en yüksek bașarım $1,07 x$, en düşük $0,98 x$, ortalama ise $1,02 x^{\prime}$ tir. 
DEÜ FMD 22(65), 315-324, 2020

Tablo 2. Başarım ölçümlerinde kullandığımız matrisler.

\begin{tabular}{|c|c|c|c|c|c|}
\hline No & Matris & $\mathbf{N}$ & NZ & $\mathrm{NZ} / \mathrm{N}$ & ASU \\
\hline 1 & ASIC_680k & 682.862 & 3.871 .773 & 5.7 & 395.259 \\
\hline 2 & cage14 & 1.505 .785 & 27.130 .349 & 18.0 & 41 \\
\hline 3 & cant & 62.451 & 2.034 .917 & 32.6 & 40 \\
\hline 4 & circuit5M & 5.558 .326 & 59.524 .291 & 10.7 & 1.290 .501 \\
\hline 5 & consph & 83.334 & 3.046 .907 & 36.6 & 66 \\
\hline 6 & cop20k_A & 121.192 & 1.362 .087 & 11.2 & 24 \\
\hline 7 & $\mathrm{dc} 2$ & 116.835 & 766.396 & 6.6 & 114.190 \\
\hline 8 & eu-2005 & 862.664 & 19.235 .140 & 22.3 & 6.985 \\
\hline 9 & fidap037 & 3.565 & 67.591 & 19.0 & 85 \\
\hline 10 & FullChip & 2.987.012 & 26.621 .990 & 8.9 & 2.312 .481 \\
\hline 11 & Ga41As41H72 & 268.096 & 9.378 .286 & 35.0 & 472 \\
\hline 12 & in-2004 & 1.382 .908 & 16.917 .053 & 12.2 & 7.753 \\
\hline 13 & ins2 & 309.412 & 1.530 .448 & 4.9 & 303.876 \\
\hline 14 & $\operatorname{lhr} 34$ & 35.152 & 764.014 & 21.7 & 63 \\
\hline 15 & mac_econ_fwd500 & 206.500 & 1.273 .389 & 6.2 & 44 \\
\hline 16 & mc2depi & 525.825 & 2.100 .225 & 4.0 & 4 \\
\hline 17 & memplus & 17.758 & 126.150 & 7.1 & 574 \\
\hline 18 & mip1 & 66.463 & 5.209 .641 & 78.4 & 713 \\
\hline 19 & pdb1HYS & 36.417 & 2.190 .591 & 60.2 & 184 \\
\hline 20 & pwtk & 217.918 & 5.926 .171 & 27.2 & 180 \\
\hline 21 & rma10 & 46.835 & 2.374 .001 & 50.7 & 145 \\
\hline 22 & $\mathrm{~s} 3 \mathrm{dkt} 3 \mathrm{~m} 2$ & 90.449 & 1.921 .955 & 21.2 & 24 \\
\hline 23 & scircuit & 170.998 & 958.936 & 5.6 & 353 \\
\hline 24 & shipsec1 & 140.874 & 3.977 .139 & 28.2 & 84 \\
\hline 25 & Si41Ge41H72 & 185.639 & 7.598 .452 & 40.9 & 531 \\
\hline 26 & Stanford & 281.903 & 2.312 .497 & 8.2 & 38.606 \\
\hline 27 & Stanford_Berkeley & 683.446 & 7.583 .376 & 11.1 & 83.448 \\
\hline 28 & webbase-1M & 1.000 .005 & 3.105 .536 & 3.1 & 4.700 \\
\hline 29 & wikipedia-20051105 & 1.634 .989 & 19.753 .078 & 12.1 & 4.970 \\
\hline 30 & wikipedia-20060925 & 2.983 .494 & 37.269 .096 & 12.5 & 5.852 \\
\hline
\end{tabular}


DEÜ FMD 22(65), 315-324, 2020

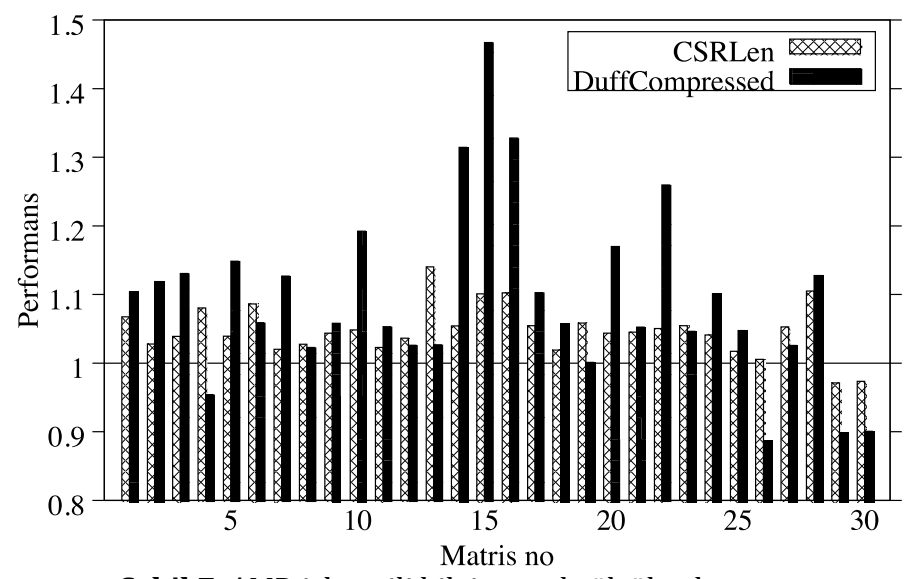

Şekil 7. AMD işlemcili bilgisayarda ölçülen başarım

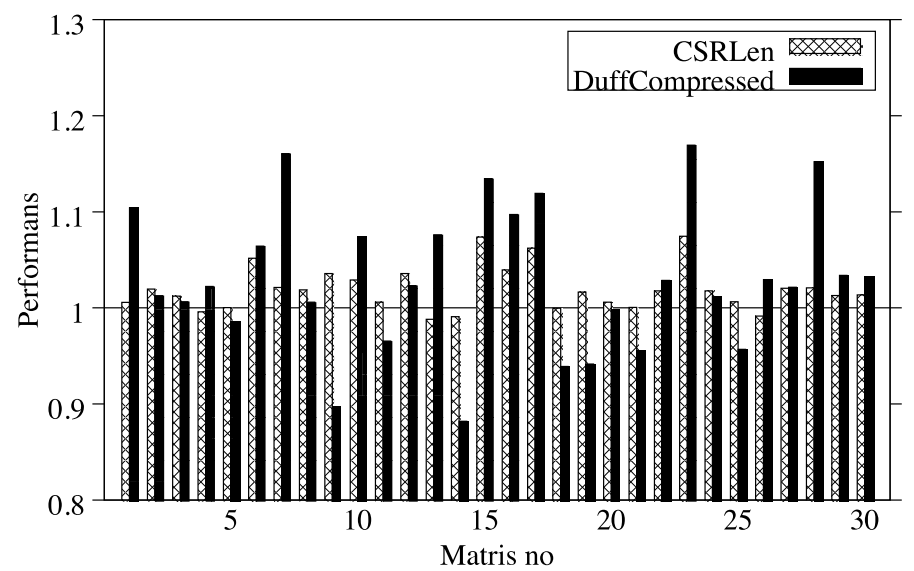

Şekil 8. Intel işlemcili bilgisayarda ölçülen başarım

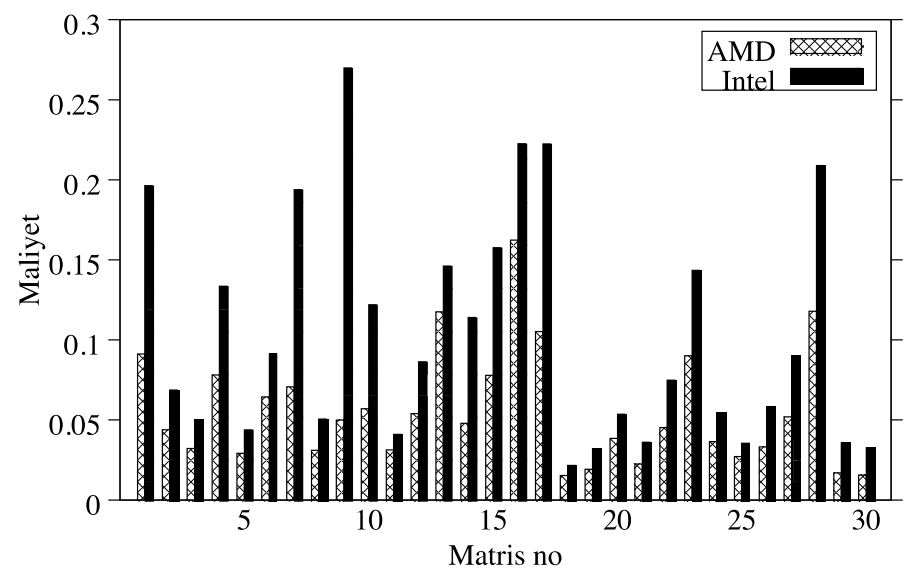

Șekil 9. Ön ișlemenin bir CSR SpMV ișlemi cinsinden maliyeti 


\section{DEÜ FMD 22(65), 315-324, 2020}

Her iki bilgisayarda alınan sonuçlara göre görülmektedir ki Duff aygıtı tabanlı yöntemle belirgin hızlanmalar almak mümkündür. CSRLen yöntemiyle yapılan kıyaslamadan anlaşılıyor ki bu hızlanmalar sadece veri sıkıştırmasından kaynaklanmamaktır.

Son olarak, DuffCompressed ${ }_{k}$ yöntemi için uygulanan ön işlemenin, yani CSR formatındaki rows dizisinin içeriğinin dönüştürülmesinin masrafını inceleyelim. Her bir matris için ön işlemede harcanan sürenin CSR yöntemiyle yapılan tek bir SpMV işleminin süresine göre normalleștirilmiș hali Șekil 9'da yer almaktadır. AMD işlemcili bilgisayarda ortalama maliyet bir SpMV koșumunun yalnızca 0,06'sı kadardır. En yüksek maliyet 0,16 SpMV koșumuna denktir. Intel üzerinde ise ortalama maliyet 0,10 iken, en yüksek 0,27 olarak ölçülmüștür. Buradan da görülmektedir ki sadece rows dizisini işleyen bir ön işlemenin maliyeti oldukça düşüktür.

\section{4. İlgili Çalışmalar}

SpMV ișleminin çok sayıda bilim alanında kullanımı olduğu için hızlandırılması halinde yaygın etkisi geniş olmaktadır. $\mathrm{Bu}$ nedenle SpMV'nin hem CPU hem de GPU mimarilerinde eniyilenmesi araștırmacıların uzun süredir üzerinde çalışageldiği bir problemdir (örneğin $[1,4-10,12,14,20,23,24])$. Konuyla ilgili yakın zamanda yayınlanmış iki tarama çalışması bulunmaktadır [2,3]. Makalemizde SpMV'nin CPU'larda çalıştırılması üzerine eğildik; GPU makalemizin kapsamı dışındadır.

Çalışmamızda CSR tabanlı SpMV işleminin maliyeti düşük bir şekilde hızlandırılması üzerine odaklandık. Matris elemanlarının yeniden sıralanması ve CSR'den daha sofistike saklama formatı kullanılmasıyla SpMV ișlemini belirgin şekilde hızlandırmak mümkün olabilir (örneğin $[1,6,7,20,24,25]$ ). Fakat bu tip yaklaşımlarda ön işleme ve format dönüşümünün maliyeti onlarca hatta yüzlerce SpMV ișlemine denk olabilmektedir $[6,7,13,24,26]$. Alınan hızlanmanın bu maliyeti karşılaması için SpMV işleminin aynı matris için yüzlerce veya binlerce kez yapılması gerekebilir. Aynı matrisle tekrar tekrar SpMV işleminin yapıldı ̆̆ı bir bağlam olan yinelemeli çözücülerde yineleme sayısı kimi zamanlar iki basamaklı sayılar mertebesinde kalabilmektedir. Böyle bağlamlarda yüksek ön işleme maliyetli SpMV yöntemleri pratik olarak faydasız hale gelmektedir. $\mathrm{Bu}$ nedenle son zamanlarda CSR formatını hiç değiştirmeden veya düşük maliyetli bir ön işlemeden geçirerek SpMV'yi hızlandırma üzerine odaklanan çalıșmalar olmuştur [12-17,27]. Bunlardan Ashari vd.'nin çalışmasında SpMV'nin GPU üzerinde koşumunun hızlandırılması için CSR formatındaki matrisin aynı uzunluktaki satırlarının bir araya getirilmesi önerilmektedir [13]. Greathouse ve Daga, yine GPU için, CSR formatındaki matris verisini iş parçacıklarına dinamik olarak dağıtan ve GPU'nun müsvedde belleğini verimli bir șekilde kullanan bir yaklașım sunmaktadır [12]. Liu ve Schmidt de LightSpMV adını verdikleri GPU kütüphanelerinde CSR formatındaki matrisi hiçbir ön işlemeden geçirmemekte, hızlanmayı dinamik yük dağılımı yaparak ve GPU'nun atomik işlemleri ile warp karma komutlarını kullanarak sağlamaktadırlar [15]. Bir başka GPU odaklı yöntem olan LSRB-CSR formatında matris datası GPU'nun mimari özelliklerine ve warp yapısına uygun olarak dilimlere ayrılmaktadır [17]. Merrill ve Garland'in makalesinde CSR formatı aynen korunmakta, eşzamanlı SpMV koşumu için matrisi mevcut yaklașımlardan daha dengeli bölüntüleyen bir yaklaşım önerilmektedir [14]; önerdikleri teknik hem GPU hem CPU için uygundur. Ohshima $v d$. farklı OpenMP çizelgeleme ayarlarının CSR tabanlı SpMV başarımına etkisini incelemişlerdir [16]. Aktemur'un çalışmasında ise CSR yöntemindeki iç döngünün tamamen açılması yaklaşımı önerilmektedir [27]. Bu yöntem SpMV kodunun belli bir CPU mimarisi için çevirim dilinde yazılmasını zorunlu kılmıștır. Bizim sunduğumuz Duff tabanlı yaklaşımda gerçekleme kaynak kod seviyesindedir. $\mathrm{Bu}$ nedenle farklı mimarilerde çalıștırmak ve derleyici optimizasyonlarından faydalanmak mümkündür.

Duff aygitı tabanlı SpMV gerçeklemesinin başarıma etkisi daha önce Youssefi'nin tezinde incelenmiștir [19]. Bu tez ile bizim makalemizin karşılaștırmasını Bölüm 2'de yapmıștık.

SpMV işlemi, matrisin her bir satırının birbirinden bağımsız olarak ișlenebileceğinden yüksek seviyede eşzamanlı hale getirilebilen bir hesaplamadır. Eşzamanlılık için uygulanan genel yaklaşım matrisin mümkün olduğunca dengeli bir şekilde eldeki iş parçacığı sayısı kadar bölüntüye ayrılmasıdır. Bunun için tek boyutlu, satır tabanlı bölüntülemeler yanında iki boyutlu yaklaşımlar da bulunmaktadır [14,28-31]. Bölüntüleme sonrasında her bir matris parçası 


\section{DEÜ FMD 22(65), 315-324, 2020}

tek iș parçacıklı bir SpMV kodu ile ișlenir. Bu sebeple, her ne kadar tek iş parçacıklı bir SpMV gerçeklemesi sunmuş olsak da önerdiğimiz teknik mevcut bölüntüleme yaklaşımları ile birleștirilerek eşzamanlı hale getirilebilir.

Duff tabanlı SpMV yönteminde rows dizisi üzerinde veri küçültmesi yapmıştık. Böylece hafızadan işlemciye taşınan verinin boyutu azalmaktadır. SpMV başarımına veri küçültmenin ve sıkıștırmanın etkisinin incelendiği çalışmalar bulunmaktadır $[23,32]$. $\mathrm{Bu}$ çalışmalarda sunulan teknikler vasitasıyla vals ve cols dizileri de sıkıștırılabilir, fakat ön işleme safhasına bu dizilerin de eklenmesi ön ișlemenin maliyetini artıracağı için bu yaklaşımları kullanmadık.

\section{Sonuç}

Yaygın etkisi yüksek olan seyrek matris-vektör çarpımı (SpMV) işlemi için Duff aygıtı ismi verilen döngü açılımı tekniğine dayalı bir gerçekleme sunduk. Bu gerçekleme kaynak kod seviyesinde yapılabilir ve farklı mimarilere derlenebilir durumdadır. Deneyse değerlendirmemizde biri AMD diğeri Intel ișlemcili iki bilgisayar üzerinde, gerçek mühendislik probleminden alınmış matrislerle başarım ölçümü yaptık; Duff tabanlı yöntem ile AMD'de 1,47, Intel'de 1,17 kata kadar hızlanma gözlemledik.

Önerdiğimiz yöntem maliyeti oldukça düșük olan bir ön işleme akabinde kullanılabilmektedir. Bu maliyet genel geçer CSR formatıyla yapılan bir SpMV işleminin ortalama 0,06'sına (AMD bilgisayarda) ve 0,10'una (Intel bilgisayarda) denktir. Düșük maliyetli ön ișleme yaklaşımı bilhassa az sayıda yinelemenin yapılacağı ve dolayısıyla yüksek ön ișleme maliyetlerinin amortize edilemediği bağlamlar için uygun olmaktadır.

Sunduğumuz çalışmanın kaynak kodunu aşağıdaki web adresinde kamuya açık olarak sunuyoruz:

\section{https://github.com/ozusrl/thundercat}

\section{Kaynakça}

[1] Williams S, Oliker L, Vuduc R, Shalf J, Yelick K, Demmel J. Optimization of Sparse Matrix-vector Multiplication on Emerging Multicore Platforms. Parallel Comput 2009;35:178-94. doi:10.1016/j.parco.2008.12.006.

[2] Filippone S, Cardellini V, Barbieri D, Fanfarillo A.
Sparse Matrix-Vector Multiplication on GPGPUs. ACM Trans Math Softw 2017;43:30:1--30:49. doi:10.1145/3017994.

[3] Langr D, Tvrdik P. Evaluation Criteria for Sparse Matrix Storage Formats. IEEE Trans Parallel Distrib Syst 2016;27:428-40. doi:10.1109/TPDS.2015.2401575.

[4] Goumas GI, Kourtis K, Anastopoulos N, Karakasis V, Koziris N. Understanding the Performance of Sparse Matrix-Vector Multiplication. 16th Euromicro Int. Conf. Parallel, Distrib. Network-Based Process., 2008, p. 283-92. doi:10.1109/PDP.2008.41.

[5] Liu X, Smelyanskiy M, Chow E, Dubey P. Efficient Sparse Matrix-vector Multiplication on x86-based Many-core Processors. Proc. 27th Int. ACM Conf. Int. Conf. Supercomput., New York, NY, USA: ACM; 2013, p. 273-82. doi:10.1145/2464996.2465013.

[6] Belgin M, Back G, Ribbens CJ. A Library for Patternbased Sparse Matrix Vector Multiply. Int J Parallel Program 2011;39:62-87. doi:10.1007/s10766010-0145-2.

[7] Liu W, Vinter B. CSR5: An Efficient Storage Format for Cross-Platform Sparse Matrix-Vector Multiplication. Proc. 29th ACM Int. Conf. Supercomput., New York, NY, USA: ACM; 2015, p. 339-50. doi:10.1145/2751205.2751209.

[8] Vuduc R, Demmel JW, Yelick KA. OSKI: A library of automatically tuned sparse matrix kernels. J Phys Conf Ser 2005;16:521. doi:10.1088/17426596/16/1/071.

[9] Bell N, Garland M. Implementing Sparse Matrixvector Multiplication on Throughput-oriented Processors. Proc. Conf. High Perform. Comput. Networking, Storage Anal., New York, NY, USA: ACM; $2009, \quad$ p. 18:1--18:11. doi:10.1145/1654059.1654078.

[10] Yzelman AN, Roose D. High-Level Strategies for Parallel Shared-Memory Sparse Matrix-Vector Multiplication. IEEE Trans Parallel Distrib Syst 2014;25:116-25. doi:10.1109/TPDS.2013.31.

[11] Saad Y. Iterative Methods for Sparse Linear Systems. SIAM; 2003. doi:10.1137/1.9780898718003.

[12] Greathouse JL, Daga M. Efficient Sparse Matrixvector Multiplication on GPUs Using the CSR Storage Format. Int. Conf. High Perform. Comput. Networking, Storage Anal. (SC'14), 2014, p. 769-80. doi:10.1109/SC.2014.68.

[13] Ashari A, Sedaghati N, Eisenlohr J, Parthasarathy S, Sadayappan P. Fast Sparse Matrix-vector Multiplication on GPUs for Graph Applications. Int. Conf. High Perform. Comput. Networking, Storage Anal. (SC '14), 2014, p. 781-92. doi:10.1109/SC.2014.69.

[14] Merrill D, Garland M. Merge-based Parallel Sparse Matrix-vector Multiplication. Int. Conf. High Perform. Comput. Networking, Storage Anal. (SC '16), 2016, p. 58:1--58:12. doi:10.1109/SC.2016.57. 


\section{DEÜ FMD 22(65), 315-324, 2020}

[15] Liu Y, Schmidt B. LightSpMV: Faster CSR-based sparse matrix-vector multiplication on CUDAenabled GPUs. Proc. Int. Conf. Appl. Syst. Archit. Process., vol. 2015-Septe, 2015, p. 82-9. doi:10.1109/ASAP.2015.7245713.

[16] Ohshima S, Katagiri T, Matsumoto M. Performance Optimization of SpMV Using CRS Format by Considering OpenMP Scheduling on CPUs and MIC IEEE Int. Symp. Embed. Multicore/Manycore SoCs, 2014, p. 253-60. doi:10.1109/MCSoC.2014.43.

[17] Liu L, Liu M, Wang C, Wang J. LSRB-CSR: A low overhead storage format for SpMV on the GPU systems. Proc. Int. Conf. Parallel Distrib. Syst. ICPADS, vol. 2016-Janua, 2016, p. 733-41. doi:10.1109/ICPADS.2015.97.

[18] Duff T. Duffs Device 1988 http://www.lysator.liu.se/c/duffs-device.html.

[19] Youssefi A. Exploring the Potential for Accelerating Sparse Matrix-Vector Product on a Processing-inMemory Architecture. Rice University, 2008.

[20] Mellor-Crummey J, Garvin J. Optimizing Sparse Matrix-Vector Product Computations Using Unrol and Jam. Int J High Perform Comput Appl 2004;18:225-36. doi: $10.1177 / 1094342004038951$.

[21] Koster J. Parallel Templates for Numerical Linear Algebra, A High-Performance Computation Library. Utrecht University, 2002.

[22] Davis TA, Hu Y. The University of Florida Sparse Matrix Collection. ACM Trans Math Softw 2011;38:1:1--1:25.

doi:10.1145/2049662.2049663.

[23] Kourtis K, Goumas G, Koziris N. Exploiting Compression Opportunities to Improve SpMxV Performance on Shared Memory Systems. ACM Trans Arch Code Optim 2010;7:16:1--16:31. doi:10.1145/1880037.1880041.

[24] Karakasis V, Gkountouvas T, Kourtis K, Goumas G, Koziris N. An Extended Compression Format for the Optimization of Sparse Matrix-Vector Multiplication. IEEE Trans Parallel Distrib Syst 2013;24:1930-40. doi:10.1109/TPDS.2012.290.

[25] Kamin S, Garzarán MJ, Aktemur B, Xu D, Yılmaz B, Chen Z. Optimization by Runtime Specialization for Sparse Matrix-vector Multiplication. Gener. Program. Concepts Exp. (GPCE '14), 2014, p. 93102. doi:10.1145/2658761.2658773

[26] Yılmaz B, Aktemur B, Garzarán MJ, Kamin S, Kıraç F. Autotuning Runtime Specialization for Sparse Matrix-Vector Multiplication. ACM Trans Arch Code Optim 2016;13:5:1--5:26. doi:10.1145/2851500

[27] Aktemur B. A sparse matrix-vector multiplication method with low preprocessing cost. Concur Comput Pract Exp 2018;30:e4701. doi:10.1002/cpe.4701.

[28] Yang W, Li K, Mo Z, Li K. Performance Optimization Using Partitioned SpMV on GPUs and Multicore
CPUs. IEEE Trans Comput 2015;64:2623-36. doi:10.1109/TC.2014.2366731.

[29] Yzelman AN, Bisseling RH. Cache-Oblivious Sparse Matrix--Vector Multiplication by Using Sparse Matrix Partitioning Methods. SIAM J Sci Comput 2009;31:3128-54. doi:10.1137/080733243.

[30] Martone M. Efficient multithreaded untransposed, transposed or symmetric sparse matrix--vector multiplication with the Recursive Sparse Blocks format. Parallel Comput 2014;40:251-70. doi:10.1016/j.parco.2014.03.008.

[31] Çatalyürek Ü V., Aykanat C. Hypergraphpartitioning-based decomposition for parallel sparse-matrix vector multiplication. IEEE Trans Parallel Distrib Syst 1999;10:673-93. doi:10.1109/71.780863.

[32] Willcock J, Lumsdaine A. Accelerating Sparse Matrix Computations via Data Compression. Proc. 20th Annu. Int. Conf. Supercomput., New York, NY, USA: ACM; 2006, p. 307-16. doi:10.1145/1183401.1183444. 